\title{
Thoracolumbar Myelomeningocele Bursting Primary Repair: Safe Multilayer Secondary Reconstruction Using a Latissimus Dorsi Muscle Flap
}

\section{Luigino Santecchia*}

Plastic and Maxillofacial Surgery Unit, Children's Hospital Bambino Gesù, Italy

*Corresponding author: Luigino Santecchia, Plastic and Maxillofacial Surgery Unit, Children's Hospital Bambino Gesù Piazza S. Onofrio, 4, 00165 Rome, Italy, Tel: +390668592365; Fax: +390668592201; E-mail: luigino.santecchia@me.net

Rec date: Apr 18, 2014; Acc date: Jul 02, 2014; Pub date: Jul 04, 2014

Copyright: (c) 2014 Santecchia L. This is an open-access article distributed under the terms of the Creative Commons Attribution License, which permits unrestricted use, distribution, and reproduction in any medium, provided the original author and source are credited.

\begin{abstract}
Study background: The authors present a case of a giant thoracolumbar myelomenigocele (T9-L5) in a newborn of 39 weeks. The goal of the procedure is to provide an amount of adequate cutaneous subcutaneous tissue, which allows an efficient coverage of the duraplasty, and reduces the risk of infections and the tissue stretching at the same time.
\end{abstract}

Methods: Closure of the defect was achieved using a patch of fascia lata and soft tissues were reconstructed using latissimus dorsi muscolar flap and a split thickness skin graft. Primary correction was performed immediately after birth, as a neurosurgical emergency. Few days after surgery, a complete dehiescence of the suture occurred.

Result: We outline here a favourable outcome of a giant MMC bursting primar repair, using the LDMF. Follow-up is now at 2 years and local conditions are excellent.

Conclusion: The use of Latissimus Dorsi Flap could be considered the first choicefor treatment of giant myelomenigocele in newborn. It gives a higher chance of getting immediately the definitive and qualitatively better repair of the defect with reduced risk of local and systemic complications.

Keywords: Myelomeningocele; Duraplasty; Spinal defect; Secondary reconstruction; Latissimus Dorsi flap; Skin graft

\section{Introduction}

The main purpose of Myelomeningocele (MMC) correction is to ensure rapid watertight closure of the dura, avoiding liquor leakage ( $16 \%$ of cases), preventing infections, such as meningitis and ventriculitis, that potentially lead to death [1].

Reconstruction is carried out as a neurosurgical emergency, and should be performed by a multidisciplinary team. The goal is to provide an amount of adequate tissue, which allows an efficient coverage of the duraplasty, and reduces the tissue stretching at the same time [2].

Most of the procedures for MMC repair are complicated by dehiscence of the flaps or vascular distress, sieromas, haematomas, pseudo-meningocele [3] and infections, which may be lethal for the young patient.

We outline here a favourable outcome of a giant MMC bursting primary repair, using the Latissimus Dorsi Muscle Flap (LDMF).

\section{Materials and Methods}

Female newborn, born at 39 weeks of gestation by cesarean section, due to twin delivery and fetal malformation. Apgar was $1^{\text {"e}}: 8$ and 5":9, weight at birth $2,850 \mathrm{Kg}$.

The patient, affected by thoracolumbar myelomeningocele of 90 $\mathrm{cm} 2(15 \times 6 \mathrm{~cm})$, was referred to the Emergency and admitted in the
Pediatric Intensive Care Unit, intubated and sedated immediately after birth. MRI revealed thoracolumbar myelomeningocele (T5-T10).

A Chiari II malformation, triventricular hydrocefalus and agenesy of the left kidney were associated to the defect. The newborn was promptly operated by the neurosurgical team.

The placode and the dorsal, lumbar and caudal roots were isolated; skin closure was initially obtained by approximation of the cleft margins towards the midline. Sixteen days after surgery, an external ventricular derivation was positioned and the partial cutaneous dehiscence of the myelomeningocele repair was sutured again on the midline.

In the following 2 weeks a complete dehiscence with partial necrosis of the wound and cerebrospinal fluid leak were evident (Figure 1); therefore, the patient was once again operated by a multidisciplinary team (plastic and neurosurgeons).

\section{Results}

The meningeal canal spine at T10 level $(1,5 \times 1 \mathrm{~cm})$ was closed using a patch of fascia lata taken from the left thigh and the soft tissues $(10 \times 5 \mathrm{~cm})$ were reconstructed using the left LDMF, transposed on its primary pedicle (Figure 2).

A single Jackson-Pratt drain was positioned in the left axilla. The patient was kept in prone position, intubated and curarized for 7 days. The postoperative period was uneventfull, drain was removed 4 days after surgery and stitches after 2 weeks. Follow-up is now at 2 years and local conditions are excellent (Figure 4). 
Citation: Santecchia L (2014) Thoracolumbar Myelomeningocele Bursting Primary Repair: Safe Multilayer Secondary Reconstruction Using a Latissimus Dorsi Muscle Flap. Surgery Curr Res 4: 198. doi:10.4172/2161-1076.1000198

Page 2 of 3

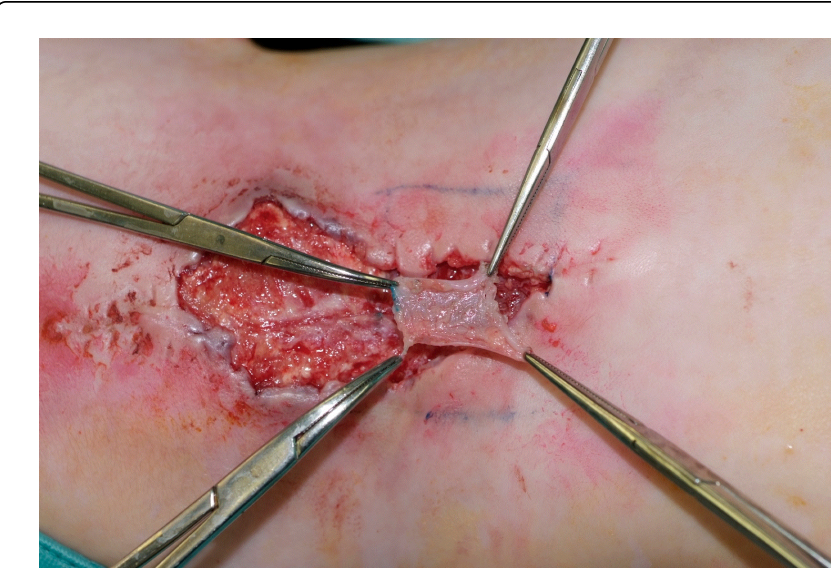

Figure 1: Fascia lata graft taken from the left thigh

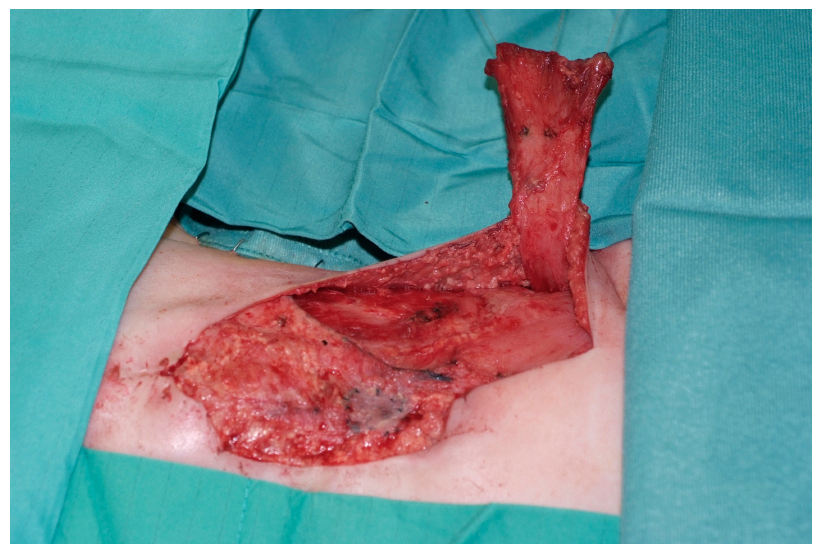

Figure 2: Preparing LD flap on its main pedicle of thoracodorsal artery

A definitive coverage was obtained by split-thickness skin grafts taken from both buttocks (Figure 3).

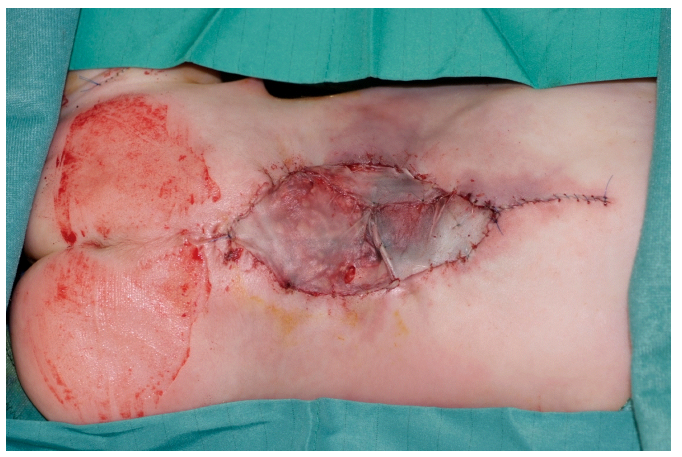

Figure 3: Final skin coverage using cutaneous thin grafts taken from the buttocks

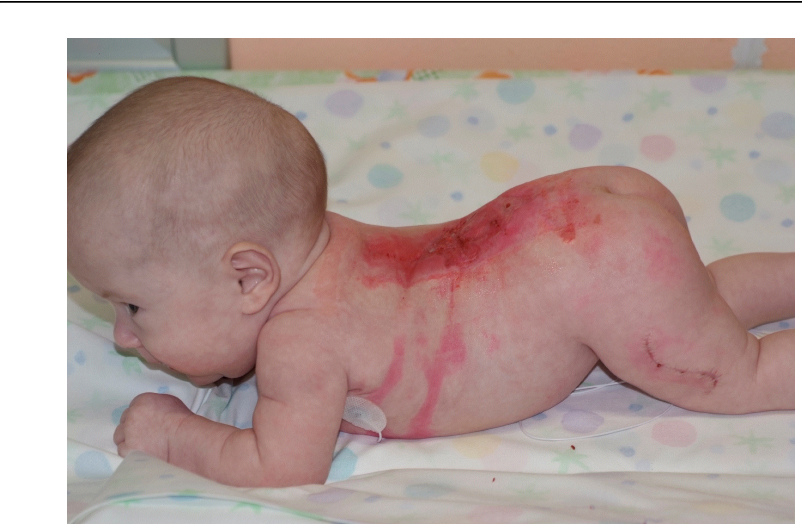

Figure 4: Follow-up at 20 days postoperative

\section{Discussion}

Several reconstructive procedures in literature are described, such as local skin flaps, expanded skin flaps, muscular and muscularaponeurotic flaps, used in combination with skin grafts and even alloplastic materials [4].

Direct approximation of the cleft margins for minor defects $(<18$ $\mathrm{cm}^{2}$ ) is described, as through careful dissection and advancement of the adjacent tissues, as using cutaneous and fasciocutaneous local flaps (double Z-plasty, V-Y advancement, rhomboid etc.) [4].

Wide defects $\left(>18 \mathrm{~cm}^{2}\right)$, need muscular or myofasciocutaneous pedicled flaps [5].

The Latissimus Dorsi Muscular Flap (LDMF) is the best choice to cover large defects from T1 to L5 because of its wide arc of rotation and great versatily. The muscular tissue fit and seal the flap over the duraplasty, reducing fistulas onset [2]. It can be also used as a reverse, as on secondary pedicles alone. After extensive dissection, the suction drain is mandatory to prevent blood serum collections that would increase the risk of infection and would weaken the duraplasty seal [6].

The chance of survival increases, if an early watertight duraplasty and a definitive coverage with a myocutaneous unit is performed [7].

The benefits of the use of muscular or myocutaneous flaps compared to other reconstructive methods such as grafts, local flaps, amniotic membranes and alloplastic materials, are related to the higher chances of getting immediately the definitive and qualitatively better repair.

\section{References}

1. Lien SC, Maher CO, Garton HJ, Kasten SJ, Muraszko KM, et al. (2010) Local and regional flap closure in myelomeningocele repair: a 15-year review. Childs Nerv Syst 26: 1091-1095.

2. McCraw JB, Penix JO, Freeman BG, Vincent MP, Wirth FH (1987) Softtissue repair of myelomeningocele defects using bilateral latissimus dorsi and trapezius musculocutaneous flaps. Ann Plast Surg 18: 147-155.

3. Zide BM, Epstein FJ, Wisoff J (1991) Optimal wound closure after tethered cord correction. Technical note. J Neurosurg 74: 673-676.

4. Ozçelik D, Yildiz KH, Iş M, Döşoğlu M. (2005) Soft tissue closure and plastic surgical aspects of large dorsal myelomeningocele defects (review of techniques). Neurosurg Rev 28: 218-225. 
Citation: Santecchia L (2014) Thoracolumbar Myelomeningocele Bursting Primary Repair: Safe Multilayer Secondary Reconstruction Using a Latissimus Dorsi Muscle Flap. Surgery Curr Res 4: 198. doi:10.4172/2161-1076.1000198

Page 3 of 3

5. Sarifakioglu N, Bingül F, Terzioglu A, Ates L, Aslan G (2003) Bilateral split latissimus dorsi V-Y flaps for closure of large thoracolumbar meningomyelocele defects. Br J Plast Surg 56: 303-306.

6. Hamid Ali M, Fazal Shaikh B, Choudhry AM (2010) Outcome of surgical reconstruction of myelomeningocele defects - a study of 25 patients. Med Chan 16: 328-330
7. Hosseinpour M, Forghani S (2009) Primary closure of large thoracolumbar myelomeningocele with bilateral latissimus dorsi flaps. J Neurosurg Pediatr 3: 331-333. 